\title{
Proso-Millet-Starch-Based Edible Films: An Innovative Approach for Food Industries
}

\author{
Sneh Punia Bangar $1, * \mathbb{C}$, Kawaljit Singh Sandhu ${ }^{2, *}$, Alexandru Vasile Rusu ${ }^{3,+}+\mathbb{C}^{\text {, Pinderpal Kaur }}{ }^{2}$, \\ Sukhvinder Singh Purewal ${ }^{2}$ D, Maninder Kaur ${ }^{4}$, Navneet Kaur ${ }^{2}$ and Monica Trif $5,+(\mathbb{D}$ \\ 1 Department of Food, Nutrition and Packaging Sciences, Clemson University, Clemson, SC 29634, USA \\ 2 Department of Food Science and Technology, Maharaja Ranjit Singh Punjab Technical University, \\ Bathinda 151001, India; pinderpa194@gmail.com (P.K.); purewal.0029@gmail.com (S.S.P.); \\ navvibhatti011@gmail.com (N.K.) \\ 3 Department of Food Science, Life Science Institute, University of Agricultural Sciences and Veterinary \\ Medicine Cluj-Napoca, 400372 Cluj-Napoca, Romania; rusu_alexandru@hotmail.com \\ 4 Department of Food Science and Technology, Guru Nanak Dev University, Amritsar 143005, India; \\ mandyvirk@rediffmail.com \\ 5 Food Research Department, Centiv GmbH, 28816 Stuhr, Germany; monica_trif@hotmail.com \\ * Correspondence: snehpunia69@gmail.com (S.P.B.); kawsandhu@rediffmail.com (K.S.S.) \\ + These authors contributed equally to this work.
}

check for updates

Citation: Punia Bangar, S.; Sandhu, K.S.; Rusu, A.V.; Kaur, P.; Purewal, S.S.; Kaur, M.; Kaur, N.; Trif, M. Proso-Millet-Starch-Based Edible Films: An Innovative Approach for Food Industries. Coatings 2021, 11, 1167. https://doi.org/10.3390/ coatings11101167

Academic Editors: Fengwei (David) Xie and Stefano Farris

Received: 15 July 2021

Accepted: 22 September 2021

Published: 27 September 2021

Publisher's Note: MDPI stays neutral with regard to jurisdictional claims in published maps and institutional affiliations.

Copyright: (c) 2021 by the authors. Licensee MDPI, Basel, Switzerland. This article is an open access article distributed under the terms and conditions of the Creative Commons Attribution (CC BY) license (https:// creativecommons.org/licenses/by/ $4.0 /)$.

\begin{abstract}
The present investigation searches for functional and antioxidant properties in proso millet starch and films. Proso millet starch was studied for its physical, chemical, morphological, and antioxidant properties. Furthermore, films were prepared from proso millet starch (native) and a starch-k-carrageenan blend. Both films were characterized for moisture content, thickness, watersolubility, opacity, water vapor permeability, and textural and antioxidant properties. The amylose content, water absorption capacity, swelling, and solubility power of the proso millet starch were $19.19 \%, 87.5 \%, 15.32 \%$, and $19 \%$, respectively. Compared to aqueous extracts $(0.68 \mathrm{mg} \mathrm{GAE} / \mathrm{g}$ and $0.36 \mathrm{mg} \mathrm{AAE} / \mathrm{g})$, the total phenolics and total antioxidant capacity were observed to be higher in methanolic starch extracts ( $0.75 \mathrm{mg} \mathrm{GAE} / \mathrm{g}$ and $0.41 \mathrm{mg}$ AAE/g). Methanol extracts of native starchbased films showed higher antioxidant activity than the film prepared using a k-carrageenan blend. The water vapor permeability and solubility of films prepared from native starch $\left(2.38 \mathrm{~g} / \mathrm{Pa} \cdot \mathrm{s} \cdot \mathrm{m}^{2}\right.$ and $28 \%$ ) were lower than those prepared using the k-carrageenan blend $\left(3.19 \mathrm{~g} / \mathrm{Pa} \cdot \mathrm{s} \cdot \mathrm{m}^{2}\right.$ and $\left.42.05 \%\right)$. The findings may be of commercial interest to pharmaceutical and food industries in producing new antioxidant-rich drugs and food products.
\end{abstract}

Keywords: proso millet starch; k-carrageenan; antioxidant properties; film; phenolics

\section{Introduction}

Proso millet (Panicum miliaceum L.) is an underutilized crop, as its potential for commercial uses is still unexplored [1]. Flour and starch from proso millet may be utilized for various industrial purposes for making food products and starch-based innovative films [2,3]. Exploring the potential of proso millet for achieving sustainability in the agricultural and food sector may open a new era for small-scale industries and marginal farmers. From an agricultural point of view, the proso millet crop is essential as per the need of its growing conditions [4,5]. The crop may tolerate limited moisture availability and harsher surrounding conditions.

During the last decade, food industries and consumers have been sensitive to the safety of food products and eco-friendly packing material features. Sufficient potential is hidden inside the different botanical resources, as their starch component may be explored to prepare biodegradable, eco-friendly packaging material (films) [6,7]. Industrially important macromolecules such as starch may replace plastic-based packing materials, as starch is present in a significant amount in natural resources. Furthermore, it may also help to 
eradicate pollutant-related issues in the environment. Additionally, starch-based packing materials (films) are safe, easy to prepare, environmentally friendly, and convenient to use [8-10]. The utilization of starch and its properties also helps to explore different botanical resources [11].

Exploring the starch used in film preparation serves as a promising technique that may ultimately enhance shelf-life safety and food products [12].

The preparation of an effective film formulation is based on two important approaches: (a) material-properties-based approach and (b) use of starch-based material on the surface of eatable materials (fruits/vegetables). Another factor that affects the successful use of starch-based films/coatings is (1) the capability of starch to form a gel and (2) the potential of starch gel to be converted into films. These experimental parameters are interrelated, making it possible to understand the starch behavior during coating/film preparation. The type and concentration of starch, along with secondary components (glycerol concentration and gum addition), also affect the reliability of films.

The potential use of millet starches for food and non-food purposes is limited. Therefore, the current study was undertaken to characterize the different millet starches and to assess their application in the formulation of films and their use as a potential source of antioxidants $[13,14]$.

Keeping in mind the importance of proso millet starch in the agricultural and food sectors, the present investigation was designed to explore the hitherto potential of proso millet for the formation of innovative films, alone and in combination with k-carrageenan gum, and characterize the physical properties, as well as antioxidant and antimicrobial activities. Gums have been extensively used in different industries as thickener, stabilizer, and gelling agents, for their biological properties, or as a source of dietary fiber-an indigestible polysaccharide [15].

The gelling power of k-carrageenan (a family of linear sulfated polysaccharides derived from Rhodophyceae red seaweeds) enhances its good brittle film-forming ability, and starch-K-carrageenan blends result in the formation of edible coating with good filmforming and mechanical properties [16-19]. Carrageenans have been studied for their bioactive activities, including antioxidant, antiviral and antibacterial, and are increasingly used for pharmaceutical, nutraceutical, and food purposes [20-23].

Moreover, diverse varieties of proso millet have been reported to have antioxidant activity and antiproliferative properties [24].

Based on previous studies investigating starch and carrageenan blends as edible films and coatings, we investigated the preparation and characterization of various proso millet starch and film properties with and without k-carrageenan addition; the obtained edible films were investigated using scanning electron microscopy, FTIR, XRD, and other important parameters during the examination. Antioxidant properties of native starch and films with k-carrageenan were compared.

\section{Materials and Methods}

\subsection{Sample Collection}

Proso millet was procured from a local market in Bathinda, India $\left(30.2110^{\circ} \mathrm{N}, 74.9455^{\circ} \mathrm{E}\right)$ (Figure 1). The grains (2.5-3 mm long and 1.75-2 mm diameter) were washed, dried (hot air oven, Rescholar, Ambala, India), and packed in an airtight box.

\subsection{Starch Isolation from Proso Millet}

Starch from proso millet (PM) grains was isolated [25]. The PM grains (800 g) were soaked in $1 / 3$ distilled water supplemented with sodium meta-bisulfate $(0.15 \%$, HiMedia, Mumbai, India) for $15 \mathrm{~h}$. Afterward, the excess water was drained off, and the grains were washed (tap water), and a slurry was prepared in a grinder (Bajaj Rex 500W, Delhi, India). The grain slurry was passed through several sieves (52 mm, $72 \mathrm{~mm}, 200 \mathrm{~mm}$, and $300 \mathrm{~mm}$ ). The starch-protein mixed slurry was kept undisturbed $(6 \mathrm{~h})$. The supernatant was removed by suction, and the starch layer was again resuspended (distilled water). Subsequently, 
the starch-water mixture was centrifuged (REMI, Mumbai, India) at $4800 \mathrm{rpm}$ for $10 \mathrm{~min}$ (thrice) using fresh distilled water. The recovered starch was then dried (hot air oven, $45^{\circ} \mathrm{C} / 12 \mathrm{~h}$ Rescholar, Ambala, India) (Figure 2).

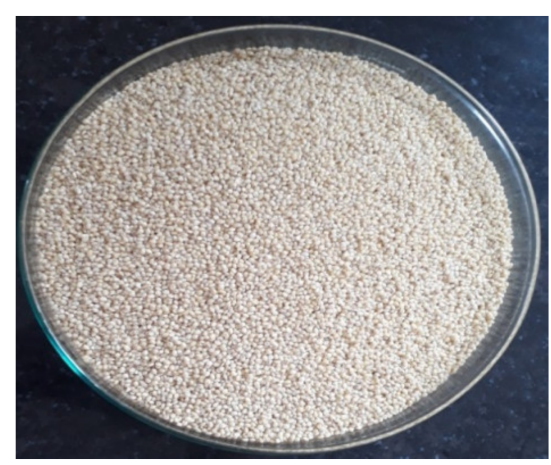

Figure 1. Proso millet grains.

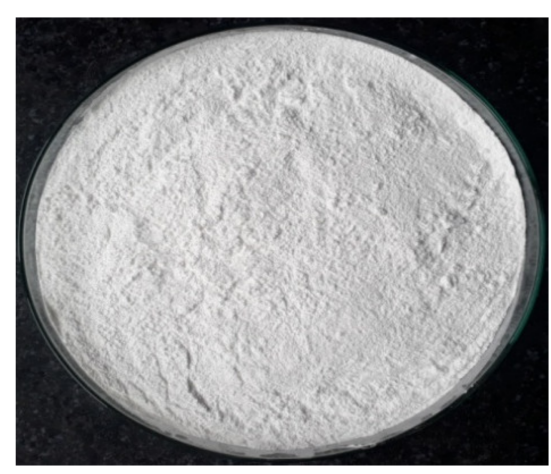

Figure 2. Proso millet starch.

\subsection{Physical and Chemical Properties of the Starch}

2.3.1. Amylose Content, Solubility and Swelling Power

The amylose content of the proso millet starch was determined [26]. A total of $20 \mathrm{mg}$ of proso millet starch was used during analysis, and $0.5 \mathrm{~N} \mathrm{KOH} \mathrm{(10} \mathrm{mL,} \mathrm{HiMedia,}$ Mumbai, India) was added, mixed well, and transferred to a volumetric flask (150 mL), followed by dilution to the mark (distilled water). A suitable amount (10 mL) was pipetted to a volumetric flask (50 mL); after that, $0.1 \mathrm{~N} \mathrm{HCl}(5 \mathrm{~mL}$, Qualigens, Mumbai, India) was added along with an iodine reagent $(500 \mu \mathrm{L}$, HiMedia, Mumbai, India). The final volume $(50 \mathrm{~mL})$ was prepared, and absorbance (UV-1800, Shimadzu, Kyoto, Japan) was noted $(625 \mathrm{~nm})$. The amylose content of the proso millet starch was determined from a standard curve (amylopectin and amylose blends). Swelling power and solubility of the proso millet starch were measured (Leach et al., 1959). The proso millet starch was added to distilled water (1:99) and heated $\left(90^{\circ} \mathrm{C} / 60 \mathrm{~min}\right)$, cooled in an ice-water bath (60 s), equilibrated ( $\left.25^{\circ} \mathrm{C} / 5 \mathrm{~min}\right)$, and centrifuged (610 g/25 min, REMI, Mumbai, India). Supernatants were drained (pre-weighed moisture dishes), evaporated $\left(100{ }^{\circ} \mathrm{C}\right)$, and cooled (room temperature) in a desiccator before reweighing.

$$
\begin{aligned}
& \text { Swelling power }(\mathrm{g} / \mathrm{g})=\frac{\text { wt.of sediments }}{\text { initial wt.of the dry starch }} \\
& \text { Solubility }(\%)=\frac{\text { wt. of dried supernatant }}{\text { Initial wt. of the dry starch }} \times 100
\end{aligned}
$$




\subsubsection{Water Binding Capacity}

The water-binding capacity of the proso millet starch was determined [27]. Starch was added to distilled water (1:5 w/v), agitated (60 $\mathrm{min})$, and centrifuged (4400 rpm/10 $\mathrm{min})$. Excess water was removed, and the wet starch was then weighed.

\subsubsection{Light Transmittance}

The light transmittance value of the proso millet starch was determined [28]. The starch suspension (1\%) was heated (water bath, Rescholar, Ambala, India at $90^{\circ} \mathrm{C} / 60 \mathrm{~min}$ ) with constant stirring. The suspension was cooled and kept undisturbed $\left(60 \mathrm{~min} / 30^{\circ} \mathrm{C}\right.$, $\mathrm{pH}$ 7). The starch sample was stored for five days at $4{ }^{\circ} \mathrm{C}$ in a refrigerator (Samsung 198L, Sriperumbudur, India), and the light transmittance in a spectrophotometer (UV-1800, Shimadzu, Kyoto, Japan) of the starch was measured every 24 h/640 nm.

\subsubsection{Film Preparation}

The formulation to prepare the different proso millet starch-based films was as follows: starch-water suspension was prepared $(1.5: 98.5 \mathrm{w} / \mathrm{v})$ and heated $\left(60^{\circ} \mathrm{C} / 15 \mathrm{~min}\right.$, water bath). In addition to the starch film, k-carrageenan gum (CG, 0.5\%, HiMedia, Mumbai, India) was dissolved in distilled water and mixed with the starch suspension. Glycerol (plasticizer, HiMedia, Mumbai, India) was added ( $25 \% \mathrm{w} / \mathrm{w}$ ) on a total solid basis (TSB). The resulting mixed-phase was stirred $(30 \mathrm{~min})$, strained through a muslin cloth, poured, kept in an oven at $60{ }^{\circ} \mathrm{C} / 30 \mathrm{~min}$, and then carefully transferred to a cabinet drier (SAd140, Pune, India) for drying at $45^{\circ} \mathrm{C} / 24 \mathrm{~h}$. Before testing, the films were peeled off and conditioned (48 h, humidity chamber (Rescholar, Ambala, India), relative humidity (50\%), and $25{ }^{\circ} \mathrm{C}$ ). Native starch films were prepared without k-carrageenan addition. The proso millet starch-based films are represented in Figure 3a,b.

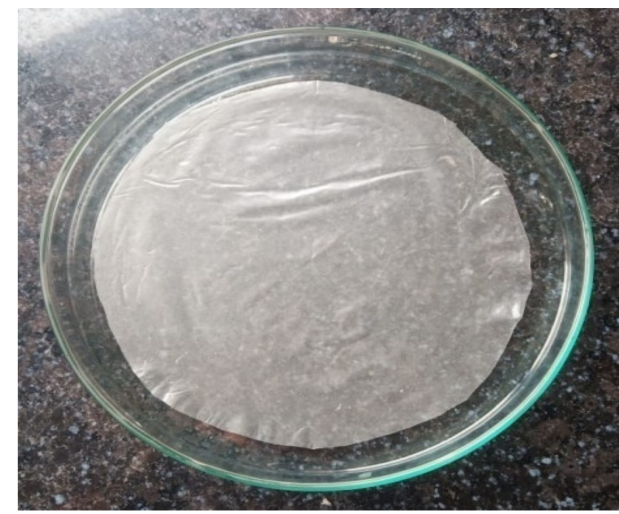

(a)

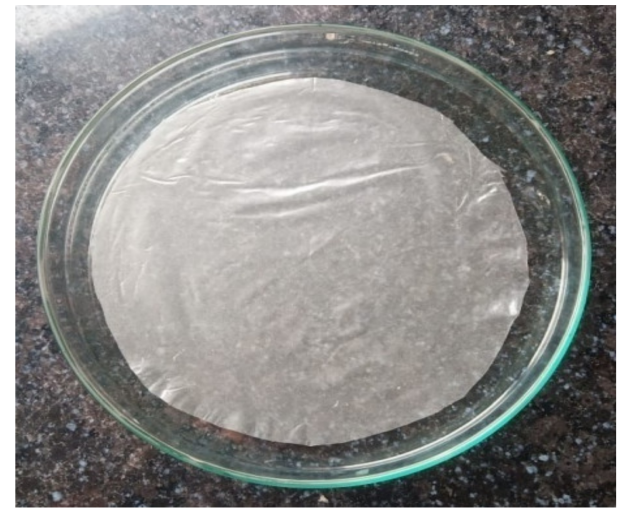

(b)

Figure 3. (a,b) Different proso millet starch films. (a) native proso millet starch film, (b) proso millet starch-k-carrageenan film.

\subsubsection{Film Thickness and Moisture Content}

The thickness of the films was measured (digital micrometer, UNIQUE VATIKA, Khokharia, India) randomly (10-12 different points) for each film, and their average was calculated. The moisture content of the starch films was also determined using a moisture analyzer (HE73, Mettler Toledo, Mumbai, India).

\subsubsection{Water Vapor Permeability}

Water vapor permeability of the proso millet starch was measured using the gravimetric modified cup method. Anhydrous $\mathrm{CaCl}_{2}$ (HiMedia, Mumbai, India) was utilized as a desiccant. Starch films were covered (sealing material) in cups, opening similar to a sealant, and were kept in a chamber $\left(30^{\circ} \mathrm{C} / 75 \%\right.$ relative humidity. The weight variation 
was noted every $120 \mathrm{~min}$ and was noted as a time function. The water vapor permeability of the starch was calculated as follows:

$$
\text { Water vapor permeability }\left(\mathrm{g} \cdot \mathrm{m} / \mathrm{Pa} \cdot \mathrm{s} \cdot \mathrm{m}^{2}\right)=\frac{\mathrm{WVTR}}{\mathrm{S}\left(\mathrm{R}_{1}-\mathrm{R}_{2}\right)} \times d
$$

where S: saturation vapor pressure of water $(\mathrm{Pa}) ; \mathrm{R}_{1}$ : \% $\mathrm{RH}$ in chamber; $\mathrm{R}_{2}$ : \% $\mathrm{RH}$ in the cup; $d$ : thickness (m).

\subsubsection{Solubility}

The solubility of the starch samples (films) was evaluated [29]. The solubility of the films was calculated as follows:

$$
\text { WS }(\%)=\left(W_{0}-W_{1}\right)=W_{0} \times 100
$$

where S: water solubility, $\mathrm{W}_{0}$ : initial weight (films); $\mathrm{W}_{1}$ : final weight (dried films)

\subsection{X-ray Diffraction (XRD)}

The XRD analysis of the proso millet starch and films was recorded $(0.154 \mathrm{~nm}$, X-ray diffractometer, Bruker, Falkenried, Germany). The conditions during the analysis were $45 \mathrm{kV}$ and $40 \mathrm{~mA}$. Diffractograms were acquired at $25^{\circ} \mathrm{C}$ over a $2 \mathrm{q}$ range of 440 , with a step size of 0.02 and a sampling interval of $10 \mathrm{~s}$.

\subsection{Scanning Electron Microscopy (SEM)}

Morphological features of the proso millet starch and films were measured [30] using a scanning electron microscope (JSM-6100, Jeol, Scotia, NY, USA). Starch and films were suspended in ethanol (HiMedia, Mumbai, India to achieve a $1 \mathrm{~g} / 100 \mathrm{~g}$ suspension. One drop of the starch-ethanol mixture was applied (aluminum stub) using double-sided adhesive tape. During the micrography, an accelerating potential $(10 \mathrm{kV})$ was used.

\subsection{Fourier Transform Infrared Spectroscopy (FTIR)}

The FTIR of the proso millet starch and films was analyzed (Cary 660, Agilent Technologies, Mulgrave, Australia). The IR region selected during the FTIR analysis was between $4000-400 \mathrm{~cm}^{-1}$. The spectra of the starch and films were recorded at room temperature under ambient conditions.

\subsection{Antioxidant Properties of Proso Millet starch and Films}

\subsubsection{Total Phenolic Content (TPC)}

The TPC of the proso millet starch and films was measured [31]. An aliquot $(100 \mu \mathrm{L})$ of starch and film extracts was allowed to react with a Folin-Ciocalteu reagent $(0.5 \mathrm{~mL}$, HiMedia, Mumbai, India), incubated for $3 \mathrm{~min}$, followed by the addition of sodium carbonate $(1.5 \mathrm{~mL}$, HiMedia, Mumbai, India), and a total volume of $10 \mathrm{~mL}$ was prepared with distilled water. The absorbance of the proso millet starch and film extracts was noted $(765 \mathrm{~nm})$, and the TPC values were expressed as $\mathrm{mg}$ gallic acid equivalents $/ \mathrm{g}$ dry weight basis (mg GAE/g dwb).

\subsubsection{DPPH Radical Scavenging Capacity Assay}

The radical scavenging capacity of the proso millet starch and film extracts was measured [32]. Briefly, $100 \mu \mathrm{L}$ of the starch and film extract was taken (spectrophotometric cell), and then a 2,2-diphenyl-1-picrylhydrazyl (DPPH) solution (3 mL, $100 \mu \mathrm{M}$, HiMedia, Mumbai, India) was added. Changes in the absorbance of the starch and film extract-DPPH mixtures were noted (517 $\mathrm{nm})$. 


\subsubsection{Total Antioxidant Capacity (TAC)}

The total antioxidant capacity (TAC) of the proso millet starch and film extracts was evaluated [33]. The absorbance of the starch and film extracts was recorded $(695 \mathrm{~nm})$. Ascorbic acid (standard, HiMedia, Mumbai, India) was used to calculate the TAC of the extracts (mg AAE/g).

\subsubsection{Condensed Tannin Content (CTC)}

The CTC of the proso millet starch and film extracts was measured [34]. The absorbance of the reaction mixture was noted $(500 \mathrm{~nm})$. Catechin (HiMedia, Mumbai, India) was used to calculate the CTC of the extracts (mg CE/100 g DWB).

\subsection{Statistical Analysis}

The data reported in the table were the average of triplicate observations. The data were subjected to one-way analysis of variance (ANOVA) and Tukey's test to assess differences among the experimental mean values $(p<0.05)$ using Minitab statistical software version 13 (Minitab Inc., State College, PA, USA).

\section{Results and Discussion}

\subsection{Functional Properties of Starch}

Estimation of functional properties helps in determining the behavior of starch under a specific set of conditions.

\subsubsection{Amylose Content, Swelling Power and Solubility}

The observed amylose content for the proso millet starch was $19.19 \%$. Singh and Adedeji [35] studied starch (proso millet) and found an amylose content of $19.39 \%$. Amylose content in starch samples has been reported to vary with the botanical source and may be affected by climatic/soil conditions during grain development [36]. The swelling power and solubility of starch significantly affect its commercial uses, as, based on these factors, the application of starch may easily be determined. The swelling capacity of proso millet starch was observed as $15.32 \%$, whereas the solubility of the starch was $19 \%$. Singh and Adedeji [35] studied native proso millet starch, and they observed a solubility of $34.88 \%$, followed by a swelling power of $24.99 \%$. The swelling power and solubility of starch samples help the food industries to determine the commercial value of starch-based products.

\subsubsection{Light Transmittance}

The clarity of starch samples may be easily determined using its light transmittance values. Light transmittance values showed a decreasing trend to increment in the storage period (days). Light transmittance values decreased from 49.4 to $14.1 \%$ during the storage duration (7 days) (Figure 4). Singh and Adediji [35] studied proso millet starch for its light transmittance values, and they observed a sharp decreasing trend in \% light transmittance (48-49\%) with an increment in the storage period. Kasemsuwanand Jane [37] concluded that phosphate-monoester derivatives are responsible for increasing starch paste clarity, whereas phospholipids are the sole reason for opaque features in the starch paste.

\subsubsection{Water Binding Capacity}

The water-binding capacity is the potential of water to create an association with hydrophilic substances in nature and the capability of a molecular matrix to entrap high amounts of water where exudation is avoided. The water-binding capacity of the starch was observed as $87.5 \%$. Olayinka et al. [38] reported a water-binding capacity of $138.4 \%$ for proso millet starch. 


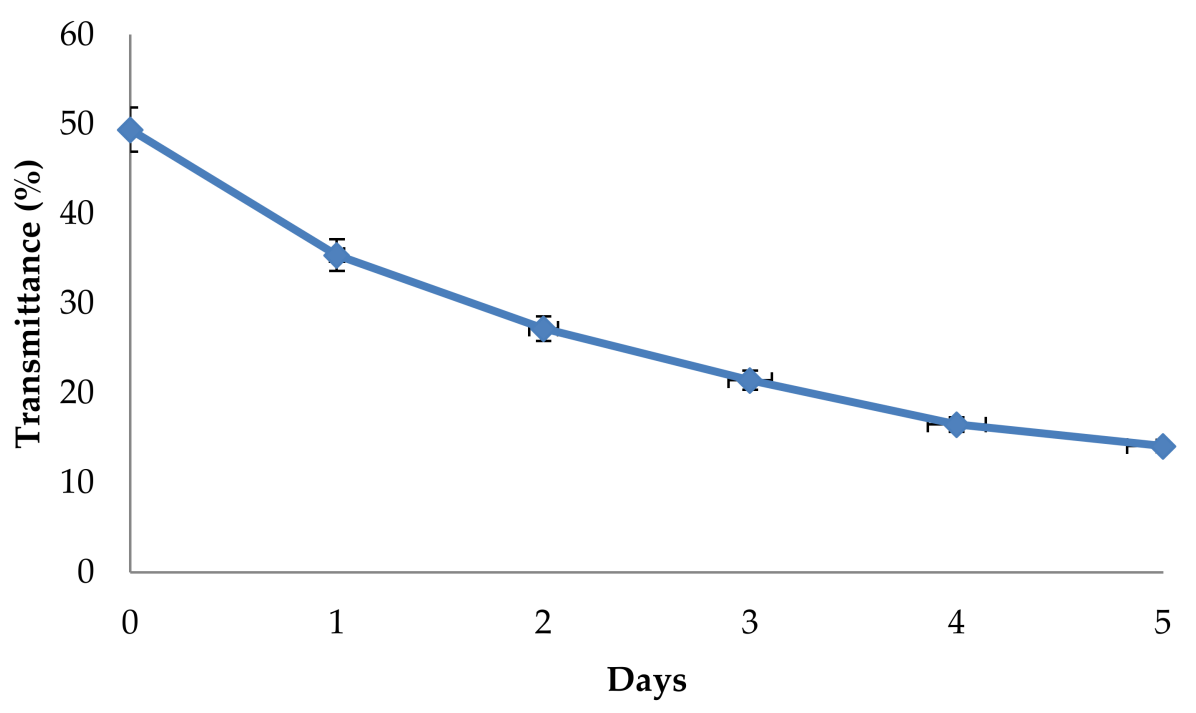

Figure 4. Light transmittance values (\%) of proso millet starch.

\subsection{Starch Film Properties}

\subsubsection{Film Thickness and Moisture Content}

Films prepared from the proso millet starch (native) and starch-k-carrageenan mixtures were studied for their thickness, which was observed as $0.091 \mathrm{~mm}$ for native starch and $0.0741 \mathrm{~mm}$ for the starch-k-carrageenan film. The moisture content of the film prepared from the native starch was $19.4 \%$, whereas, for the starch-k-carrageenan film, it was $29 \%$. The variation in moisture content was similar to that observed for the proso millet starch-k-carrageenan films. We believe it is very difficult to remove water molecules that are tightly bound with other macromolecules, e.g., hydrates of glucose, etc. Free water and water molecules that are less tightly bound can be removed with ease using instant moisture meters or a hot air oven. Sandhu et al. [39] studied the film-forming potential of pearl millet starch (native) and a starch-k-carrageenan mixture. They observed the thickness of the film, which was in the range of $0.10-0.19 \mathrm{~mm}$. Ahmad et al. [40] observed a decrease in the moisture content of the film (rice flour) during the addition of fish gelatin.

\subsubsection{Water Vapor Permeability}

Water vapor permeability is a commercial aspect of films that determines the potential of a food packaging material to thwart/restrict the moisture transmission rate from the immediate atmosphere to the food. Due to their hydrophilic nature, starch-based films are generally prone to water vapor permeability. Water vapor permeability of the proso millet starch film was observed as $2.38 \mathrm{~g} / \mathrm{Pa} \cdot \mathrm{s} \cdot \mathrm{m}^{2}$, whereas for the starch-k-carrageenan mixture film, it was $3.19 \mathrm{~g} / \mathrm{Pa} \cdot \mathrm{s} \cdot \mathrm{m}^{2}$. The studied property could be used to estimate the water gain/loss by the food wrapped in the particular film. Such films could be recommended for packing fresh leafy vegetables. Water vapor permeability is considered the most relevant property of edible films, as it helps determine the capability of the food package to slow down the rate of moisture transmission [41]. Sukhija et al. [42] observed a decrease in the water vapor permeability value with a rising concentration of both starch and k-carrageenan.

\subsubsection{Solubility}

The solubility of films is considered an integral property that directly affects its possible uses in food industries. Some food materials/products may require water-insoluble films to maximize their shelf life/integrity and resistance toward the water. However, in some other cases, film solubility in water before product consumption could prove to be useful, such as encapsulation of food/additives. However, these types of films could be usefully exploited as packaging material for food products designed specifically to be consumed along with 
food products such as candy wrappers, where they ease the process of dissolution in the consumer's mouth. Proso millet starch and starch-k-carrageenan mixture films were studied for their solubility. The solubility of the films was $28 \%$ for the native film, while it was $42.05 \%$ for the starch-k-carrageenan film. Sukhija et al. [42] demonstrated a decreasing trend in film solubility with an increment in starch concentration. Almasi et al. [43] found that the use of glycerol results in reduced intermolecular bonding, which ultimately weakens the film's network, thereby resulting in higher solubility values. Cuqet al. [44] demonstrated that the plasticizer's hydrophilic nature helps reduce the interactions among biopolymer molecules. Ultimately, enhanced water entrapped in the matrix (polymer) further provides mobile regions and enhanced solubility values.

\subsection{SEM}

SEM graphs of the proso millet starch and starch-k-carrageenan mixture films are depicted in Figure 5a-c. Compared to the films prepared using the starch-k-carrageenan mixture, those prepared using native starch showed a smoother appearance. The micrographs obtained during SEM represent more homogeneity of the structure in the proso millet starch film, whereas the film prepared from the mixture showed a coarser, rough, and somewhat irregular surface. Garcia et al. [45] stated that regular phase in the matrix (polymeric) results in strong/stable molecular interactions. The dense structure of films with structural solidity may be the reason for the significant mechanical properties such as tensile strength.

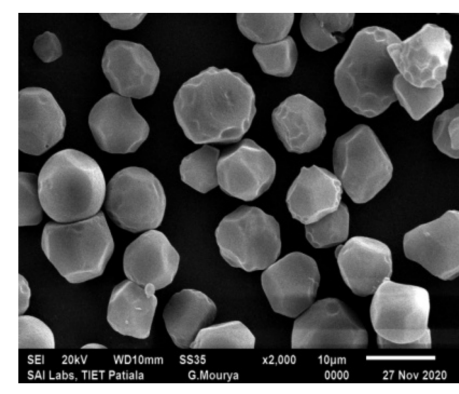

(a)

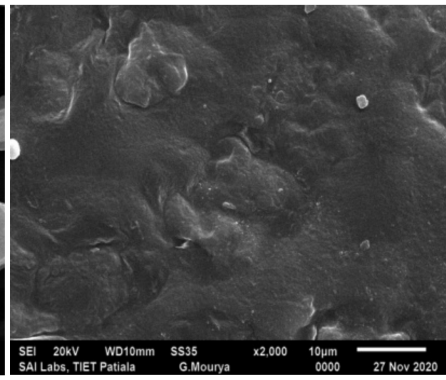

(b)

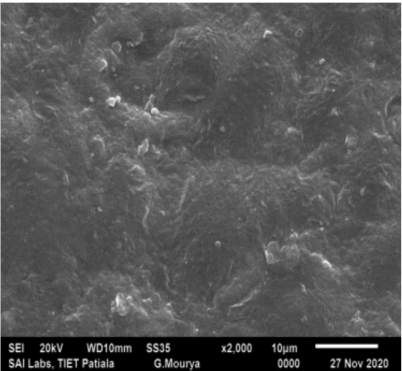

(c)

Figure 5. (a) Scanning electron microscopy of proso millet starch, (b) native film, and (c) starch-kcarrageenan film.

\subsection{FTIR}

FTIR of the proso millet starch films (native and starch-k-carrageenan mixture) was performed to check the level of interactions (Figure 6).

During the FTIR analysis of the proso millet starch, different peaks were observed. The peak at $480.49 \mathrm{~cm}^{-1}$ indicates the polysulfides (S-S stretch) group; $525.35 \mathrm{~cm}^{-1}$ and $572.35 \mathrm{~cm}^{-1}$ represent aliphatic iodo compounds (C-I); $704.19 \mathrm{~cm}^{-1}$ and $762.14 \mathrm{~cm}^{-1}$ represent aliphatic chloro compounds $(\mathrm{C}-\mathrm{Cl}) ; 859.07 \mathrm{~cm}^{-1}$ represents peroxides $(\mathrm{C}-\mathrm{O}-$ $\mathrm{O}$ - stretch); $928.89 \mathrm{~cm}^{-1}$ represents aliphatic phosphates (P-O-C stretch); $1009.77 \mathrm{~cm}^{-1}$, $1077.88 \mathrm{~cm}^{-1}$, and $1149.10 \mathrm{~cm}^{-1}$ represent aliphatic fluoro compounds $(\mathrm{C}-\mathrm{F}) ; 1336.59 \mathrm{~cm}^{-1}$ represents primary or secondary (OH in-plane bend group); $1638.92 \mathrm{~cm}^{-1}$ represents primary amine (NH bend); $2109.00 \mathrm{~cm}^{-1}$ indicates cyanide ions, thiocyanate ions, and related ions; $2888.99 \mathrm{~cm}^{-1}$ represents methoxy (C-H stretch $\left(\mathrm{CH}_{3}-\mathrm{O}-\right)$; $3276.54 \mathrm{~cm}^{-1}$ represents ammonium ions. Shi et al. [46] reported significant stretching of $\mathrm{C}-\mathrm{H}$ (asymmetric) at $2971 \mathrm{~cm}^{-1}$ and the absorption band $\left(1458 \mathrm{~cm}^{-1}\right)$. This was described to be due to the binding of water in the starch granules. Zhang et al. [47] observed specific bands $\left(1417 \mathrm{~cm}^{-1}\right.$, $1600 \mathrm{~cm}^{-1}$, and $3400 \mathrm{~cm}^{-1}$ ), which showed variation during the retrogradation process, suggesting a reduction in an amorphous region, followed by enhancement in the structural level organization. 


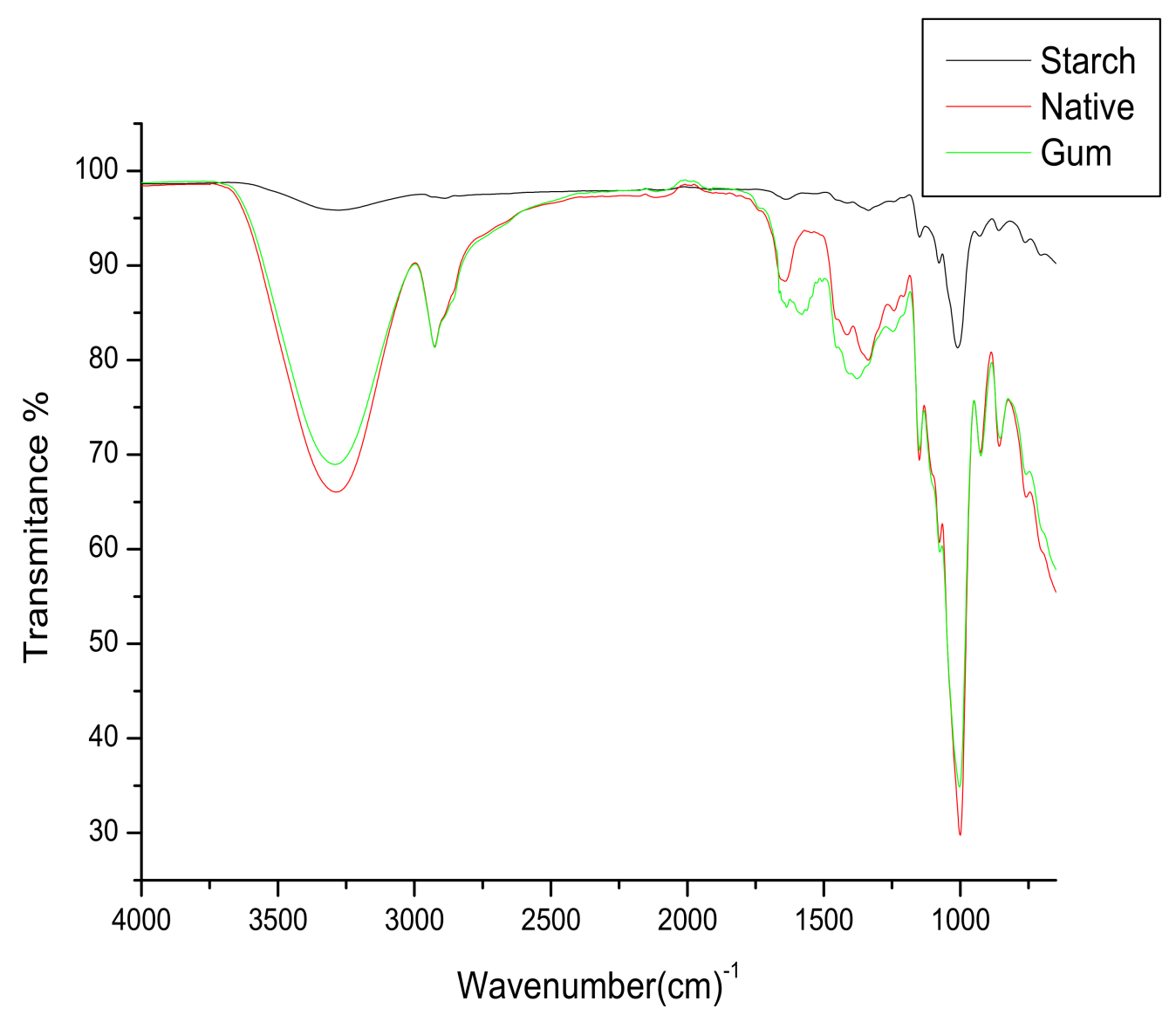

Figure 6. FTIR of proso millet starch, native film, and starch-k-carrageenan film.

During the FTIR analysis, different native film peaks were observed. The peak at $479.79 \mathrm{~cm}^{-1}$ represents polysulfides (S-S stretch) group; $522.54 \mathrm{~cm}^{-1}$ and $559.28 \mathrm{~cm}^{-1}$ represent aliphatic iodo compounds (C-I stretch); $758.51 \mathrm{~cm}^{-1}$ represents aliphatic chloro compounds (C-Cl); $857.38 \mathrm{~cm}^{-1}$ represents peroxides (C-O-O- stretch); $926.25 \mathrm{~cm}^{-1}$ represents aliphatic phosphates (P-O-C stretch); $1076.30 \mathrm{~cm}^{-1}$ and $1149.93 \mathrm{~cm}^{-1}$ represent aliphatic fluoro compounds (C-F); $1242.90 \mathrm{~cm}^{-1}$ represents epoxy and oxirane rings; $1337.37 \mathrm{~cm}^{-1}$ represents primary or secondary (OH in-plane bend group); $1414.34 \mathrm{~cm}^{-1}$ represents carboxylate (carboxylic acid salt); $1641.39 \mathrm{~cm}^{-1}$ represents primary amine (NH bend); $1985.25 \mathrm{~cm}^{-1}$ represents aromatic combination bands; $2113.25 \mathrm{~cm}^{-1}$ represents different ions such as thiocyanate, cyanide, and related derivatives; $2925.98 \mathrm{~cm}^{-1}$ represents methoxy, $\mathrm{C}-\mathrm{H}$ stretch $\left(\mathrm{CH}_{3}-\mathrm{O}-\right) ; 3287.98 \mathrm{~cm}^{-1}$ represents ammonium ions.

During the FTIR analysis of the CG film, different peaks were observed. The peak at $479.93 \mathrm{~cm}^{-1}$ represents the polysulfides (S-S stretch) group; $521.67 \mathrm{~cm}^{-1}$ and $558.75 \mathrm{~cm}^{-1}$ represent aliphaticiodo compounds (C-I stretch); $758 \mathrm{~cm}^{-1}$ represents aliphatic chloro compounds (C-Cl); $854.55 \mathrm{~cm}^{-1}$ represents peroxides (C-O-O-) stretch; $924.62 \mathrm{~cm}^{-1}$ represents aliphatic phosphates (P-O-C stretch); $1074.84 \mathrm{~cm}^{-1}$ and $1149.68 \mathrm{~cm}^{-1}$ represent aliphatic fluoro compounds (C-F); $1246.13 \mathrm{~cm}^{-1}$ represents epoxy and oxirane rings; $1378.25 \mathrm{~cm}^{-1}$ represents primary or secondary (OH in-plane bend); $1505.38 \mathrm{~cm}^{-1}$ represents $(\mathrm{C}=\mathrm{C}-\mathrm{C})$ aromatic ring stretch; $1580.24 \mathrm{~cm}^{-1}$ represents secondary amine $(>\mathrm{N}-\mathrm{H}$ bend $)$; $1636.53 \mathrm{~cm}^{-1}$ represents primary amine (NH bend); $1662.91 \mathrm{~cm}^{-1}$ and $1914.05 \mathrm{~cm}^{-1}$ show aromatic combination bands; $2113.80 \mathrm{~cm}^{-1}$ represents cyanide ion, thiocyanate ion, and related ions; $2925.71 \mathrm{~cm}^{-1}$ represents methoxy, C-H stretch $\left(\mathrm{CH}_{3}-\mathrm{O}-\right)$; $3290.07 \mathrm{~cm}^{-1}$ represents ammonium ions. Guan et al. [48] observed that the inclusion of k-carrageenan results in shifting absorption bands toward $3280 \mathrm{~cm}^{-1}$ and $2922 \mathrm{~cm}^{-1}$, which ultimately showed blending. Ramos et al. [49] demonstrated specific bands at 998 to $1148 \mathrm{~cm}^{-1}$, corresponding to $\mathrm{C}-\mathrm{C}$ and $\mathrm{C}-\mathrm{O}$ bond vibrations. Gutierrez et al. [50] demonstrated that the 
starch-based film represents specific bands at $3326 \mathrm{~cm}^{-1}$, corresponding to $\mathrm{O}-\mathrm{H}$ stretching in glycerol, starch, and water.

Guan et al. [48] demonstrated that when two different components are allowed to be mixed in a suitable ratio, the physical blends vs. chemical interactions are significantly affected by changes in the specific peaks of the spectra. k-carrageenan addition in starch results in a shifting of absorption bands from $3280 \mathrm{~cm}^{-1}$ to $2922 \mathrm{~cm}^{-1}$, confirming the blending level. Wu et al. [51] observed shifting bands at the peak at $1727 \mathrm{~cm}^{-1}$, which showed stronger interactions (high cross-linking with proso millet starch, glycerol, and k-carrageenan).

\subsection{XRD}

The proso millet starch and films were studied for XRD analysis, and their results are represented in Figure 7. XRD results represent a "classic A" type pattern, which is a characteristic feature of grains starch with a characteristic reflection at $2 \theta$ of $15.16^{\circ}, 17.38^{\circ}$, $18.08^{\circ}, 20.18^{\circ}$, and $22.98^{\circ}$. XRD results for the native film also represent a "classic $\mathrm{A}^{\prime \prime}$ type pattern, which is a reflection at $2 \theta$ of $15.46^{\circ}, 17.38^{\circ}, 18.2^{\circ}, 20.36^{\circ}$, and $23.08^{\circ}$. The starch-k-

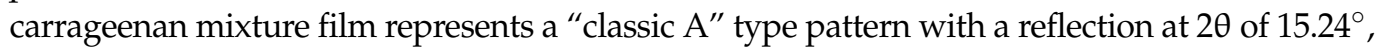
$17.26^{\circ}, 18.04^{\circ}, 20.18^{\circ}$, and $23.18^{\circ}$. The native film and the starch-k-carrageenan film also had a "classic $A^{\prime \prime}$ type pattern with one more reflection at $2 \theta$ of $32.02^{\circ}$ and $32^{\circ}$, respectively.

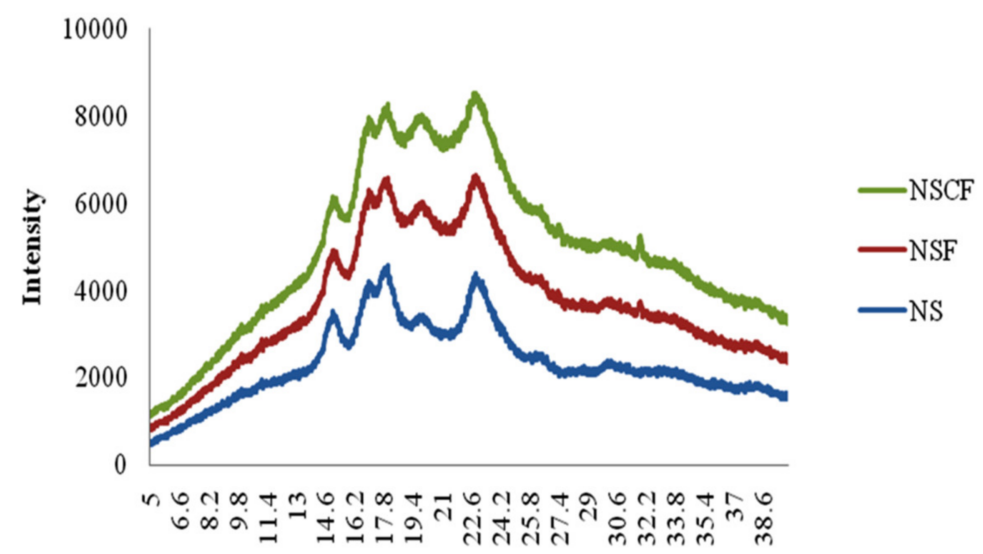

\section{Diffraction angle $(2 \theta)$}

Figure 7. X-ray diffraction of proso millet starch, native film (NSF), and k-carrageenan film (NSCF).

\subsection{Antioxidant Properties of the Proso Millet Starch and Films \\ 3.6.1. TPC and CTC}

Proso millet starch, native film, and starch-k-carrageenan film were studied to detect the total phenolic content (TPC) in them. Two different extraction phases (aqueous and methanol) were selected to extract bioactive compounds from the studied samples. A higher TPC value was observed in the methanol-starch extract $(0.75 \mathrm{mg} \mathrm{GAE} / \mathrm{g})$, followed by the water-starch extract $(0.68 \mathrm{mg} \mathrm{GAE} / \mathrm{g})$, water-native film extract $(0.54 \mathrm{mg} \mathrm{GAE} / \mathrm{g})$, water-starch-k-carrageenan film extract $(0.47 \mathrm{mg}$ GAE $/ \mathrm{g})$, methanol-native film extract (0.46 mg GAE/g), and methanol-starch-k-carrageenan film extract $(0.39 \mathrm{mg} \mathrm{GAE} / \mathrm{g})$, respectively (Table 1). The results showed that the methanol phase acts as an efficient solvent for bioactive compounds. The lowest TPC value was observed in the methanolstarch-k-carrageenan film extract $(0.39 \mathrm{mg}$ GAE/g). The proso millet starch possesses a significant number of bioactive metabolites responsible for the antioxidant properties in the films. Baek and Song [52] reported a $13.3 \mathrm{mg} \mathrm{GAE} / \mathrm{g}$ film TPC value in films prepared using proso millet starch with $3 \%$ added curcumin. The TPC value of millets makes them an attractive substrate for commercial uses, as many health-benefiting products of pharmaceutical importance may be prepared from them. TPC values may vary with the cultivar type, varietal difference, and geographical distribution [53]. Chandrasekara and 
Shahidi [54] reported a TPC value of $114.03 \mu \mathrm{mol}$ ferulic acid equiv/g in extracts prepared from Kodo millet. Baek and Song [52] concluded that the TPC in aqueous extracts of proso millet was 2-12 $\mu \mathrm{mol} \mathrm{FAE/g} \mathrm{cooked} \mathrm{grain.}$

Table 1. Antioxidant and bioactive compounds in the proso millet starch and films.

\begin{tabular}{cccccc}
\hline $\begin{array}{c}\text { Extraction } \\
\text { Phase }\end{array}$ & $\begin{array}{c}\text { Sample } \\
\text { Type }\end{array}$ & $\begin{array}{c}\text { TPC } \\
\text { (mgGAE/g) }\end{array}$ & $\begin{array}{c}\text { CTC } \\
\text { (mgCE/100 g) }\end{array}$ & $\begin{array}{c}\text { DPPH } \\
\text { (\%)Inhibition) }\end{array}$ & $\begin{array}{c}\text { TAC } \\
\text { (mg AAE/g) }\end{array}$ \\
\hline \multirow{3}{*}{ Water } & Starch & $0.68^{\mathrm{d}} \pm 0.06$ & $0.60^{\mathrm{b}, \mathrm{c}} \pm 0.04$ & $3.68^{\mathrm{d}} \pm 0.11$ & $0.36^{\mathrm{b}, \mathrm{c}} \pm 0.05$ \\
& Native film & $0.54^{\mathrm{c}} \pm 0.04$ & $0.52^{\mathrm{b}} \pm 0.09$ & $3.14^{\mathrm{c}} \pm 0.16$ & $0.27^{\mathrm{b}} \pm 0.08$ \\
& Starch-k-carrageenan film & $0.47^{\mathrm{b}} \pm 0.08$ & $0.41^{\mathrm{a}} \pm 0.02$ & $2.95^{\mathrm{b}} \pm 0.21$ & $0.21^{\mathrm{a}} \pm 0.04^{\mathrm{d}}$ \\
\hline \multirow{3}{*}{ Methanol } & Starch & $0.75^{\mathrm{e}} \pm 0.03$ & $0.69^{\mathrm{c}} \pm 0.04$ & $3.71^{\mathrm{d}} \pm 0.25$ & $0.41^{\mathrm{c}} \pm 0.07$ \\
& Native film & $0.46^{\mathrm{b}} \pm 0.05$ & $0.54^{\mathrm{b}} \pm 0.08$ & $2.98^{\mathrm{b}} \pm 0.19$ & $0.29^{\mathrm{b}} \pm 0.05$ \\
& Starch-k-carrageenan film & $0.39^{\mathrm{a}} \pm 0.03$ & $0.45^{\mathrm{a}} \pm 0.05$ & $2.62^{\mathrm{a}} \pm 0.14$ & $0.24^{\mathrm{a}} \pm 0.03$ \\
\hline
\end{tabular}

Values ( \pm Standard deviation) are means of triplicate determination. Means followed by the same letter in superscript in a column do not differ significantly $(p<0.05)$.

Different extracts (starch, native film, and starch-k-carrageenan film) were studied to detect their CTC. Two different solvents (water and methanol) were selected. The CTC value was observed higher in the methanol-starch extract $(0.69 \mathrm{mg} \mathrm{CE} / 100 \mathrm{~g})$, followed by the water-starch extract $(0.60 \mathrm{mg} \mathrm{CE} / 100 \mathrm{~g})$, methanol-native film extract $(0.54 \mathrm{mg}$ $\mathrm{CE} / 100 \mathrm{~g})$, water-native film extract $(0.52 \mathrm{mg} \mathrm{CE} / 100 \mathrm{~g})$, methanol-starch-k-carrageenan film extract $(0.45 \mathrm{mg} \mathrm{CE} / 100 \mathrm{~g}) \mathrm{m}$, and water-starch-k-carrageenan film extract $(0.41 \mathrm{mg}$ $\mathrm{CE} / 100 \mathrm{~g}$ ), respectively. The aqueous extract showed the lowest CTC value (starch-kcarrageenan film $0.41 \mathrm{mg}$ CE/100 g). Kumari et al. [55] observed a higher CTC in the foxtail cultivar (CO7), $34.47 \mathrm{mg} \mathrm{CE} \mathrm{/100} \mathrm{g.}$

\subsubsection{DPPH Assay and TAC}

Proso millet starch, native film, and starch-k-carrageenan film were studied for $\%$ DPPH inhibition. Two different extraction phases (aqueous and methanol) were selected to explore the antioxidant potential. The \% DPPH inhibition was observed to be higher in the methanol-starch extract (3.71\%), followed by the water-starch extract $(3.68 \%)$, water-native film extract $(3.14 \%)$, methanol-native film extract $(2.98 \%)$, water-starch-k-carrageenan film extract $(2.95 \%)$, and methanol-starch-k-carrageenan film extract $(2.62 \%)$. The lowest $\%$ DPPH inhibition was observed in the methanol extract (CG film 2.62\%). Baek and Song [52] observed that proso millet starch films prepared using curcumin showed significant $\%$ DPPH inhibition properties. Furthermore, increasing the concentration of curcumin from 0.5 to $3 \%$ resulted in an enhancement of \% scavenging activity from 11.85 to $42.96 \%$. They reported a variation in DPPH inhibition as 0.93-4.74 $\mu \mathrm{mol} \mathrm{TE} / \mathrm{g} \mathrm{DW}$, which varied with the processing of foxtail millet. Chandrasekara and Shahidi [54] observed that millet extracts during the DPPH assay and showed varying values (1.9-16.2, 4.9-33.5, 59.3-84.6, 12.3-114, and 17-32.7 $\mu \mathrm{mol} \mathrm{FAE/g)} \mathrm{in} \mathrm{response} \mathrm{to} \mathrm{processing} \mathrm{methods} \mathrm{such} \mathrm{as} \mathrm{cooked}$ grain (aqueous, $\mathrm{pH}$ treated, gastric digested, GI digested and fermentation, respectively). Foti and Ruberto [56] promulgated that the transfer of electrons during the DPPH assay may influence the equilibrium of bioactive metabolites, affecting the reaction rate and resulting values.

Different extracts (starch, native film, and starch-k-carrageenan film) were studied to detect TAC in them. Two different extraction phases (aqueous and methanol) were selected to extract bioactive compounds from the studied samples. Higher TAC was observed in methanol-starch extract $(0.41 \mathrm{mg} \mathrm{AAE} / \mathrm{g})$, followed by the water-starch extract $(0.36 \mathrm{mg} \mathrm{AAE} / \mathrm{g})$, methanol-native film extract $(0.29 \mathrm{mg} \mathrm{AAE} / \mathrm{g})$, water-native film extract $(0.27 \mathrm{mg} \mathrm{AAE} / \mathrm{g})$, methanol-starch-k-carrageenan film extract $(0.24 \mathrm{mg} \mathrm{AAE} / \mathrm{g})$, and water-CG film extract $(0.21 \mathrm{mg} \mathrm{AAE} / \mathrm{g})$. The lowest TAC value was observed in the aqueous starch-k-carrageenan film extract $(0.21 \mathrm{mg} \mathrm{AAE} / \mathrm{g})$. Colored varieties of 
millets grain and natural colorants are recommended for commercial use to prepare healthbenefiting supplements $[57,58]$.

\section{Conclusions}

The objective of the present study, given the economic importance of proso millet starch and starch-k-carrageen-based films, was to characterize their physical, chemical, morphological, structural, and antioxidant properties. The results indicated that native starch and starch-k-carrageenan films had similar to "classic A" type pattern with a reflection at $2 \theta$ of $32.02^{\circ}$ and $32^{\circ}$, respectively. The micrographs obtained during SEM represent more homogeneity of the structure in the starch film. In contrast, the starchk-carrageenan-based films blends showed a coarser, rougher, and somewhat irregular surface. Moreover, methanol extracts of native starch films exhibited higher antioxidant activity than the film prepared using the starch blended with k-carrageenan. It can be concluded that proso millet starch may serve as a good alternative in producing edible and biodegradable films and coatings with bioactive properties to maintain food safety and extend shelf life, which is very important for different potential industrial applications.

Author Contributions: Conceptualization, S.S.P.; data curation, N.K.; formal analysis, S.P.B., K.S.S. and S.S.P.; funding acquisition, K.S.S.; investigation, S.S.P. and N.K.; methodology, P.K. and N.K.; project administration, K.S.S.; resources, P.K. and N.K.; software, A.V.R., M.K. and M.T.; supervision, K.S.S. and S.S.P.; validation, K.S.S.; writing-original draft, S.P.B., S.S.P. and N.K.; writing-review \& editing, S.P.B., K.S.S., A.V.R., M.K. and M.T. All authors have read and agreed to the published version of the manuscript.

Funding: This research received no external funding.

Institutional Review Board Statement: Not applicable.

Informed Consent Statement: Not applicable.

Data Availability Statement: Data is contained within the article.

Conflicts of Interest: The authors declare no conflict of interest.

\section{References}

1. Dietrich, T.; Velasco, M.V.; Echeverría, P.; Pop, B.; Rusu, A. Crop and plant biomass as valuable material for BBB. Alternatives for valorization of green wastes. In Biotransformation of Agricultural Waste and by-Products: The Food, Feed, Fibre, Fuel (4F) Economy; Elsevier: San Diego, CA, USA, 2016.

2. Li, K.; Zhang, T.; Narayanamoorthy, S.; Jin, C.; Sui, Z.; Li, Z.; Li, S.; Wu, K.; Liu, G.; Corke, H. Diversity analysis of starch physicochemical properties in 95 proso millet (Panicum miliaceum L.) accessions. Food Chem. 2020, 324, 126863. [CrossRef] [PubMed]

3. Sanderson, E.; Duizer, L.M.; McSweeney, M.B. Descriptive analysis of a new proso millet product. Int. J. Gastron. Food Sci. 2017, 8, 14-18. [CrossRef]

4. Gong, X.; Dang, K.; Lv, S.; Zhao, G.; Tian, L.; Luo, Y.; Feng, B. Interspecific root interactions and water-use efficiency of intercropped proso millet and mung bean. Eur. J. Agron. 2020, 115, 126034. [CrossRef]

5. Zhang, Y.; Han, H.; Zhang, D.; Li, J.; Gong, X.; Feng, B.; Xue, Z.; Yang, P. Effects of ridging and mulching combined practices on proso millet growth and yield in semi-arid regions of China. Field Crop. Res. 2017, 213, 65-74. [CrossRef]

6. Vianna, T.C.; Marinho, C.O.; Junior, L.M.; Ibrahim, S.A.; Vieira, R.P. Essential oils as additives in active starch-based food packaging films: A review. Int. J. Biol. Macromol. 2021, 182, 1803-1819. [CrossRef]

7. Cai, C.; Ma, R.; Duan, M.; Deng, Y.; Liu, T.; Lu, D. Effect of starch film containing thyme essential oil microcapsules on physicochemical activity of mango. LWT_Food Sci. Technol. 2020, 131, 109700. [CrossRef]

8. Zarski, A.; Bajer, K.; Raszkowska-Kaczor, A.; Rogacz, D.; Zarska, S.; Kapusniak, J. From high oleic vegetable oils to hydrophobic starch derivatives: II. Physicochemical, processing and environmental properties. Carbohydr. Polym. 2020, 243, 116499. [CrossRef]

9. Volpe, V.; De-Feo, G.; De Marco, I.; Pantani, R. Use of sunflower seed fried oil as an ecofriendly plasticizer for starch and application of this thermoplastic starch as a filler for PLA. Ind. Crop. Prod. 2018, 122, 545-552. [CrossRef]

10. Goudarzi, V.; Shahabi-Ghahfarrokhi, I.; Babaei-Ghazvini, A. Preparation of ecofriendly UV-protective food packaging material by starch/ $\mathrm{TiO}_{2}$ bio-nanocomposite: Characterization. Int. J. Biol. Macromol. 2017, 95, 306-313. [CrossRef]

11. Bangar, S.P.; Siroha, A.K.; Nehra, M.; Trif, M.; Ganwal, V.; Kumar, S. Structural and Film-Forming Properties of Millet Starches: A Comparative Study. Coatings 2021, 11, 954. [CrossRef] 
12. Zhang, R.; Wang, X.; Cheng, M. Preparation and Characterization of Potato Starch Film with Various Size of $\mathrm{Nano}^{-S i O}$. Polymers 2018, 10, 1172. [CrossRef]

13. Kalam Azad, M.O.; Jeong, D.I.; Adnan, M.; Salitxay, T.; Heo, J.W.; Naznin, M.T.; Lim, J.D.; Cho, D.H.; Park, B.J.; Park, C.H. Effect of Different Processing Methods on the Accumulation of the Phenolic Compounds and Antioxidant Profile of Broomcorn Millet (Panicum miliaceum L.) Flour. Foods 2019, 8, 230. [CrossRef]

14. Chandrasekara, A.; Naczk, M.; Shahidi, F. Effect of processing on the antioxidant activity of millet grains. Food Chem. 2012, 133, 1-9. [CrossRef]

15. Farooq, M.; Azadfar, E.; Rusu, A.; Trif, M.; Poushi, M.K.; Wang, Y. Improving the Shelf Life of Peeled Fresh Almond Kernels by Edible Coating with Mastic Gum. Coatings 2021, 11, 618. [CrossRef]

16. Abdou, E.S.; Sorour, M.A. Preparation and characterization of starch/carrageenan edible films. Int. Food Res. J. 2014, 21, 191-195.

17. Al-Hashimi, A.G.; Ammar, A.B.; Govindan, L.; Cacciola, F.; Lakhssassi, N. Development of a Millet Starch Edible Film Containing Clove Essential Oil. Foods 2020, 9, 184. [CrossRef] [PubMed]

18. Lauer, M.K.; Smith, R.C. Recent advances in starch-based films toward food packaging applications: Physicochemical, mechanical, and functional properties. Compr. Rev. Food Sci. Food Saf. 2020, 19, 1-53. [CrossRef]

19. Rusu, A.V.; Criste, F.L.; Mierliţă, D.; Socol, C.T.; Trif, M. Formulation of Lipoprotein Microencapsulated Beadlets by Ionic Complexes in Algae-Based Carbohydrates. Coatings 2020, 10, 302. [CrossRef]

20. Davydova, V.N.; Sorokina, I.V.; Volod'ko, A.V.; Sokolova, E.V.; Borisova, M.S.; Yermak, I.M. The Comparative Immunotropic Activity of Carrageenan, Chitosan and Their Complexes. Mar. Drugs 2020, 18, 458. [CrossRef]

21. Falcó, I.; Randazzo, W.; Sánchez, G.; López-Rubio, A.; Fabra, M.J. On the use of carrageenan matrices for the development of antiviral edible coatings of interest in berries. Food Hydrocoll. 2019, 92, 74-85. [CrossRef]

22. Pacheco-Quito, E.-M.; Ruiz-Caro, R.; Veiga, M.-D. Carrageenan: Drug Delivery Systems and Other Biomedical Applications. Mar. Drugs 2020, 18, 583. [CrossRef] [PubMed]

23. Mitrea, L.; Calinoiu, L.F.; Precup, G.; Bindea, M.; Rusu, B.; Trif, M.; Ferenczi, L.J.; Stefanescu, B.E.; Vodnar, D.C. Inhibitory Potential of Lactobacillus Plantarum on Escherichia coli. Bull. UASVM Food Sci. Technol. 2017, 74. [CrossRef]

24. Zhang, L.; Liu, R.; Niu, W. Phytochemical and antiproliferative activity of proso millet. PLoS ONE 2014, 9, e104058. [CrossRef] [PubMed]

25. Sandhu, K.S.; Singh, N. Some properties of corn starches II: Physicochemical, gelatinization, retrogradation, pasting and gel textural properties. Food Chem. 2007, 101, 1499-1507. [CrossRef]

26. Williams, P.C.; Kuzina, F.D.; Hlynka, I. Rapid colorimetric procedure for estimating the amylose content of starches and flours. Cereal Chem. 1970, 47, 411-420.

27. Yamazaki, W.T. An alkaline water retention capacity test for the evaluation of cookies in baking potentialities of soft winter wheat flours. Cereal Chem. 1953, 30, 242-246.

28. Craig, S.A.S.; Maningat, C.C.; Seib, P.A.; Hoseney, R.C. Starch paste clarity. Cereal Chem. 1989, 66, $173-182$.

29. Romero-Bastida, C.A.; Bello-Pérez, L.A.; García, M.A.; Martino, M.N.; Solorza-Feria, J.; Zaritzky, N.E. Physicochemical and microstructural characterization of films prepared by thermal and cold gelatinization from non-conventional sources of starches. Carbohydr. Polym. 2005, 60, 235-244. [CrossRef]

30. Kaur, M.; Singh, N.; Sandhu, K.S.; Guraya, H.S. Physicochemical, morphological, thermal and rheological properties of starches separated from kernels of some Indian mango cultivars (Mangifera indica L.). Food Chem. 2004, 85, 131-140. [CrossRef]

31. Yu, J.; Fleming, S.L.; Williams, B.; Williams, E.V.; Li, Z.; Somma, P.; Rieder, C.L.; Goldberg, M.L. Greatwall kinase: A nuclear protein required for proper chromosome condensation and mitotic progression in Drosophila. J. Cell Biol. 2004, 16, 487-492. [CrossRef]

32. Yen, G.C.; Chen, H.Y. Antioxidant Activity of Various Tea Extracts in Relation to Their Antimutagenicity. J. Agric. Food Chem. 1995, 43, 27-32. [CrossRef]

33. Prieto, P.; Pineda, M.; Aguilar, M. Spectrophotometric quantitation of antioxidant capacity through the formation of a phosphomolybdenumcomplex: Specific application to the determination of vitamin E. Anal. Biochem. 1999, 269, 337-341. [CrossRef]

34. Julkunen-Titto, R. Phenolics constituents in the leaves of northern willos: Methods for the analysis of certain phenolics. J. Agric. Food Chem. 1985, 33, 213-217. [CrossRef]

35. Singh, M.; Adedeji, A.A. Physicochemical and functional properties of proso millet starch. Starch/Staerke 2016, 61, 1165-1174.

36. Singh, N.; Kaur, L.; Sandhu, K.S.; Kaur, J.; Nishinari, K. Relationships between physicochemical, morphological, thermal, rheological properties of rice starches. Food Hydrocoll. 2006, 20, 532-542. [CrossRef]

37. Kasemsuwan, T.; Jane, J. A quantitative method for the survey of starch phosphate derivatives and starch phospholipids by 31P nuclear magnetic resonance spectroscopy. Cereal Chem. 1996, 73, 702-707.

38. Olayinka, O.O.; Adebowale, K.O.; Olu-Owolabi, B.I. Effect of heat-moisture treatment on physicochemical properties of white sorghum starch. Food Hydrocoll. 2008, 22, 225-230. [CrossRef]

39. Sandhu, K.S.; Sharma, L.; Kaur, M.; Kaur, R. Physical, structural and thermal properties of composite edible films prepared from pearl millet starch and carrageenan gum: Process optimization using response surface methodology. Int. J. Biol. Macromol. 2020, 143, 704-713. [CrossRef]

40. Ahmad, M.; Hani, N.M.; Nirmal, N.P.; Fazial, F.F.; Mohtar, N.F.; Romli, S.R. Optical and thermo-mechanical properties of composite films based on fish gelatin/rice flour fabricated by casting technique. Prog. Org. Coat. 2015, 84, 115-127. [CrossRef] 
41. Shaikh, M.; Haider, S.; Ali, T.M.; Hasnain, A. Physical, thermal, mechanical and barrier properties of pearl millet starch films as affected by levels of acetylation and hydroxypropylation. Int. J. Biol. Macromol. 2019, 124, 209-219. [CrossRef]

42. Sukhija, S.; Singh, S.; Riar, C.S. Analyzing the effect of whey protein concentrate and psyllium husk on various characteristics of biodegradable film from lotus (Nelumbo nucifera) rhizome starch. Food Hydrocoll. 2016, 60, 128-137. [CrossRef]

43. Almasi, H.; Ghanbarzadeh, B.; Entezami, A.A. Physicochemical properties of starch-CMC-nanoclay biodegradable film. Int. J. Biol. Macromol. 2010, 46, 1-5. [CrossRef]

44. Cuq, B.; Gontard, N.; Cuq, J.L.; Guilbert, S. Rheological model for the mechanical properties of myofibrillar protein-based films. J. Agric. Food Chem. 1996, 44, 1116-1122. [CrossRef]

45. García, N.L.; Famá, L.; Dufresne, A.; Aranguren, M.; Goyanes, S. A comparison between the physico-chemical properties of tuber and cereal starches. Food Res. Int. 2009, 42, 976-982. [CrossRef]

46. Shi, A.M.; Wang, L.J.; Li, D.; Benu, A. The effect of annealing and cryoprotectants on the properties of vacuum-freeze dried starch nanoparticles. Carbohydr. Polym. 2012, 88, 1334-1341. [CrossRef]

47. Zhang, H.; Tian, Y.; Bai, Y.; Xu, X.; Jin, Z. Structure and properties of maize starch processed with a combination of $\alpha$-amylase and pullulanase. Int. J. Biol. Macromol. 2013, 52, 38-44. [CrossRef] [PubMed]

48. Guan, Y.; Liu, X.; Zhang, Y.; Yao, K. Study of phase behavior on chitosan/viscose rayon blend film. J. Appl. Polym. Sci. 1998, 67, 1965-1972. [CrossRef]

49. Ramos, O.L.; Reinas, I.; Silva, S.I.; Fernandes, J.C.; Cerqueira, M.A.; Pereira, R.N.; Vicente, A.A.; Pocas, M.F.; Pintado, M.E.; Malcata, F.X. Effect of whey protein purity and glycerol content upon physical properties of edible films manufactured there from. Food Hydrocoll. 2013, 30, 110-122. [CrossRef]

50. Gutiérrez, T.J.; Toro-Márquez, L.A.; Merino, D.; Mendieta, J.R. Hydrogen-bonding interactions and compostability of bionanocomposite films prepared from corn starch and nano-fillers with and without added Jamaica flower extract. Food Hydrocoll. 2019, 89, 283-293. [CrossRef]

51. Wu, J.; Zhong, F.; Li, Y.; Shoemaker, C.F.; Xia, W. Preparation and characterization of pulullan-chitosan and pullulancarboxymethyl chitosan blended films. Food Hydrocoll. 2013, 30, 82-91. [CrossRef]

52. Baek, S.K.; Song, K.B. Characterization of active biodegradable films based on proso millet starch and curcumin. Starch/Stärke 2018, 71, 3-4. [CrossRef]

53. Salar, R.K.; Purewal, S.S. Phenolic content, antioxidant potential and DNA damage protection of pearl millet (Pennisetum glaucum) cultivars of North Indian region. Food Meas. 2017, 11, 126-133. [CrossRef]

54. Chandrasekara, A.; Shahidi, F. Bioaccessibility and antioxidant potential of millet grain phenolics as affected by simulated in vitro digestion and microbial fermentation. J. Funct. Food 2012, 4, 226-237.

55. Kumari, D.; Madhujith, T.; Chandrasekara, A. Comparison of phenolic content and antioxidant activities of millet varieties grown in different locations in Sri Lanka. Food Sci. Nutr. 2017, 5, 474-485. [CrossRef]

56. Foti, M.; Ruberto, G. Kinetic solvent effects on phenolic antioxidant determined by spectrophotometric measurements. J. Agric. Food Chem. 2001, 49, 342-348. [CrossRef]

57. Das, S.; Khound, R.; Santra, M.; Santra, D.K. Beyond Bird Feed: Proso Millet for Human Health and Environment. Agriculture 2019, 9, 64 .

58. Dasa, F.; Binh, L.N. A Comparative Study on Rheological, Functional and Color Properties of Improved Millet Varieties and Injera. J. Agric. Sci Food Res. 2019, 10, 1-8. [CrossRef] 